\title{
Identifikasi Salience Stakeholders dalam Pengungkapan Sustainability Report
}

\author{
Ni Putu Ayu Devi Yanti' \\ Fakultas Ekonomi dan Bisnis \\ Universitas Udayana, Indonesia
}

\author{
Gayatri ${ }^{2}$ \\ Fakultas Ekonomi dan Bisnis \\ Universitas Udayana, Indonesia
}

\begin{abstract}
Surel : yanthidevi@gmail.com
ABSTRAK

Stakeholder memiliki karakteristik tersendiri dalam pendekatan memahami kepentingannya. Dalam menyeimbangkan kebutuhan dan keinginan stakeholders, terdapat berbagai kendala salah satunya adalah tingkat pengaruh stakeholder yaitu salience stakeholder. Penelitian ini dilakukan pada perusahaan di Bursa Efek Indonesia periode tahun 2017-2019 melalui web resmi $w w w . i d x . c o . i d$. Populasi penelitian berjumlah 632 perusahaan dengan pengambilan sampel menggunakan teknik purposive sampling sebanyak 43 perusahaan dengan data observasian sebanyak 129 . Teknik analisis penelitian adalah analisis regresi linier dan uji two way ANOVA. Hasil penelitian menunjukkan pemegang saham dan kelompok pecinta lingkungan berpengaruh positif dan signifikan pada luas pengungkapan sustainability report sedangkan konsumen serta media masa yang memiliki atribut legitimasi dan power berpengaruh negatif dan signifikan pada luas pengungkapan sustainability report.
\end{abstract}

Kata Kunci: Salience; Stakeholders; Pengungkapan Sustainability Report.

\section{Identification of Salience Stakeholders in the Sustainability Report Disclosure}

\begin{abstract}
Stakeholders have their own characteristics in their approach to understanding their interests. In balancing the needs and desires of stakeholders, there are various obstacles, one of which is the level of stakeholder influence, namely stakeholder salience. This research was conducted on companies on the Indonesia Stock Exchange for the period 2017-2019 through the official website www.idx.co.id. The population of this research is 632 companies. Samples are taken using purposive sampling technique as many as 43 companies with 129 observational data. The research analysis technique is linear regression analysis and two way ANOVA test. The results showed that shareholders and environmental groups had a positive and significant effect on the disclosure area of the sustainability report, while consumers and the mass media which had the attributes of legitimacy and power had a negative and significant effect on the disclosure area of the sustainability report.
\end{abstract}

Keywords: Salience; Stakeholders; Sustainability Report Disclosures.

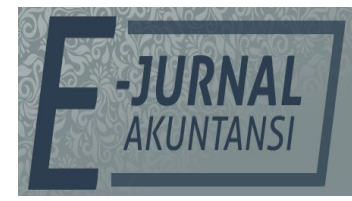

e-ISSN 2302-8556

Vol. 31 No. 8

Denpasar, Agustus 2021

Hal. 2058-2071

DOI:

10.24843/EJA.2021.v31.i08.p14

PENGUTIPAN:

Yanti, N.P.A.D., \& Gayatri, G. (2021). Identifikasi Salience Stakeholders dalam

Pengungkapan Sustainability Report. E-Jurnal Akuntansi, 31(8), 2058-2071

RIWAYAT ARTIKEL:

Artikel Masuk: 10 Juni 2021 Artikel Diterima: 25 Agustus 2021

Artikel dapat diakses : https://ojs.unud.ac.id/index.php/Akuntansi/index 


\section{PENDAHULUAN}

Dewasa ini organisasi atau perusahaan dituntut untuk ikut berperan dalam pembangunan berkelanjutan untuk memenuhi kebutuhan dunia sekarang tanpa mengabaikan kemampuan generasi mendatang dalam memenuhi kebutuhannya (Safitri, 2019;7). Oleh karenanya, perusahaan perlu membuat suatu laporan keberlanjutan (sustainability report) agar pembangunan keberlanjutan ini dapat terukur, transparan, serta terlaksana maka dilakukan pengungkapan atas sustainability report (Simbolon \& Sueb, 2016). Sustainability report bagi perusahaan merupakan informasi yang mencerminkan kinerja dari sebuah organisasi dalam dimensi ekonomi, sosial, dan lingkungan (ACCA, 2013); (Dewi \& Sudana, 2015); (Sejati \& Prastiwi, 2015).

Menurut konsep triple bottom line dalam sustainability report dapat dipahami sebagai cara perusahaan untuk memberikan informasi kepada stakeholders yang nantinya akan menilai kinerja perusahaan sehubungan dengan masing - masing aspek ekonomi, kinerja sosial, dan lingkungan (Bradford et al., 2017). Stakeholder adalah individu atau kelompok yang memiliki kepentingan terhadap keputusan serta aktivitas organisasi (Langrafe et al., 2020). Menurut Freeman (1984), pemangku kepentingan (stakeholder) tersebut beberapa diantaranya meliputi pemegang saham, karyawan, konsumen, pemerintah, media masa, masyarakat lokal, pemasok, kelompok pecinta lingkungan, dan kelompok kepentingan khusus.

Keseimbangan dari sebuah konflik yang terjadi pada stakeholder dan pemenuhan kebutuhannya menjadi tujuan bagi perusahaan yang digambarkan dengan teori stakeholder (Man, 2015). Namun dalam menyeimbangkan kebutuhan dan keinginan stakeholders, terdapat berbagai kendala yang dihadapi oleh perusahaan, yang disebut sebagai stakeholder saliency atau Salience Stakeholder (Mitchell et al, 1997). Salience didefinisikan sebagai tingkatan dimana perusahaan memberikan prioritasnya untuk membandingkan tingkat pengaruh stakeholders dan mengidentifikasi bahwa atribut kekuasaan (power), legitimasi dan urgensi yang dimiliki oleh para stakeholders membuat mereka lebih menonjol atau lebih salience daripada yang lain.

Menurut peraturan POJK Nomor 51/POJK.03//2017 di Indonesia yang diterbitkan oleh Otoritas Jasa Keuangan (OJK 2017), lembaga-lembaga seperti jasa bidang keuangan, sebuah emiten, serta perusahaan publik harus melaporkan sebuah sustainability reporting atau laporan berkelanjutannya. Mereka yang melanggar ketentuan itu akan dikenakan sanksi administratif berupa teguran atau peringatan tertulis. Sayangnya sustainability reporting (SR) hanya dibuat oleh beberapa perusahaan dengan rincian sebanyak 30\% saja dari 100 top perusahaan sudah mendaftar pada Bursa Efek Indonesia (BEI) (Ernest \& Young 2016). Data terbaru dari Bursa Efek Indonesia (BEI) dan Global Reporting Initiative (GRI) menunjukkan hasil bahwa dari total 629 Perusahaan Tercatat per 23 April 2019, hanya sebanyak 110 sustainability report yang telah diterbitkan atau hanya 17 persen saja.

Tanpa adanya suatu dukungan dari pihak stakeholders, maka perusahaan usahanya tak jalan, bahkan tiap sektor yang memiliki stakeholder dengan tingkat salience tertinggi yang berbeda (Fernandez-Feijoo et al., 2014). Mirip dengan penelitian Sweeney \& Coughlan (2008) menjelaskan di beberapa bidang 
perusahaan seperti telekomunikasi dengan kecantikan stakeholder pentingnya sama yakni pelanggan, sedangkan pada bidang minyak dan otomotif yang sama di stakeholder pentingnya yakni lingkungan (Rudyanto \& Siregar, 2018).

Dalam penelitian Sejati \& Prastiwi (2015), dibandingkan dengan para stakeholder yang lain, seorang yang punyak hak milik (shareholder) akan perusahaan atau nama lain pemegang saham bisa dipredikat sebagai stakeholder penting. Jadi, semakin tinggi tekanan dari investor, semakin tinggi pula pengungkapan sustainability report yang dihasilkan perusahaan. Pemegang saham khususnya pemegang saham dominan akan cenderung mengambil keputusan yang dapat memaksimalkan tindakan ekonomi, sosial, dan lingkungan. Selanjutnya mereka akan menuntut perusahaan untuk melakukan pengungkapan atas tindakan tersebut. Jadi, semakin tinggi tekanan dari investor, semakin tinggi pula pengungkapan sustainability report yang dihasilkan perusahaan. Penelitian yang dilakukan oleh Hamudiana \& Achmad (2017) mengungkapkan bahwa semakin tinggi tekanan dari stakeholder maka perusahaan akan meningkatkan transparansi pengungkapan sustainability report.

$\mathrm{H}_{1 \mathrm{a}}$ : Pemegang Saham Berpengaruh Terhadap Pengungkapan Sustainability Reporting.

Aset yang paling berharga bagi perusahaan tidak hanya dilihat dari asset yang dapat diukur saja, melainkan dapat dilihat melalui aset yang tidak dapat diukur seperti intellectual capital atau sumber daya manusia, salah satunya adalah karyawan. Saat ini baik karyawan maupun calon karyawan akan memperhatikan apakah perusahaan tempat mereka bekerja merupakan perusahaan yang bertanggung jawab sosial atau tidak. Karyawan yang berkualitas tentu telah mengerti akan pentingnya tanggung jawab sosial perusahaan. Kehilangan karyawan yang berkualitas ini tentu akan menyebabkan operasional perusahaan dapat terguncang. Salah satu cara agar karyawan mengetahui pemenuhan tanggung jawab sosial yang telah dilakukan perusahaan terhadap karyawannya adalah mereka akan menjadikan sustainability report sebagai alat informasi. Hal tersebut tentu akan memberikan perasaan positif kepada karyawan seperti bangga, antusias, dan puas (Dissanayake et al., 2016) dan (Huang \& Kung, 2010). Rudyanto et al. (2018) menyebutkan bahwa karyawan sebagai stakeholder perusahaan mempunyai pengaruh positif terhadap sustainability report. Perusahaan beranggapan bahwa aset mereka yang paling berharga salah satunya adalah karyawan. Betts et al. (2015) serta Sun \& Yu (2015) mengungkapkan bahwa karyawan dalam perusahaan yang melaksanakan dan mengungkapkan tanggung jawab sosial melalui sustainability report akan berkeja lebih baik dibandingkan dengan perusahaan yang tidak melaksanakan tanggung jawab sosial dan mengungkapkan sustainability report (Alfaiz \& Aryati, 2019).

$\mathrm{H}_{1 \mathrm{~b}}$ : Karyawan Berpengaruh Terhadap Tingkat Pengungkapan Sustainability Report.

Perusahaan dengan dekekatan konsumen yang tinggi cenderung akan menghasilkan sustainability report dengan transparansi yang tinggi pula. Perusahaan tersebut dianggap memperoleh tekanan sosial untuk bertindak dengan baik dan menyediakan informasi mengenai tanggung jawab sosial. Perusahaan akan berfokus untuk meningkatkan image perusahaan yang dapat mempengaruhi penjualan melalui pengungkapan tanggung jawab sosialnya. 
Fernandez-Feijoo et al. (2014) mengungkapkan kedekatan konsumen dengan perusahaan mendorong perusahaan untuk berusaha meningkatkan brand image dengan meningkatkan transparansi pengungkapan sustainability reportnya.

$\mathrm{H}_{1 \mathrm{c}}$ : Konsumen Berpengaruh Terhadap Pengungkapan Sustainability Report.

Pemerintah merupakan bagian dari stakeholder yang dianggap paling mempengaruhi perusahaan (Şener et al., 2016). Kehadiran dari kepemilikan saham pemerintah cenderung memperbaiki tingkat pengungkapan sustainability report perusahaan (Akrout \& Othman, 2013). Li et al. (2016) juga menemukan bahwa pemerintah termasuk stakeholder yang paling penting dalam mempengaruhi tanggung jawab sosial karena memberikan tekanan yang lebih besar. Perintah pengungkapan dampak dari aktivitas perusahaan membuat lebih mudah bagi pemerintah dan kelompok yang berkepentingan untuk menekan perusahaan dalam menjalankan praktik tanggung jawab sosial (He et al., 2018).

$\mathrm{H}_{1 \mathrm{~d}}$ : Pemerintah Berpengaruh Terhadap Pengungkapan Sustainability Report.

Pengkomunikasian tanggung jawab sosial melalui media akan meningkatkan reputasi perusahaan di mata masyarakat (A.P \& Hardiningsih, 2015). Menurut Harmoni (2010), media adalah sumber daya pada informasi lingkungan. Menurut Munif et al. (2010), perusahaan dapat mengungkapkan kegiatan tanggung jawab sosial melalui berbagai media. Terdapat tiga media yang sering dipakai perusahaan dalam pengungkapan tanggung jawab sosial, yaitu melalui media televisi, koran, serta internet (website perusahaan). Penelitian yang dilakukan oleh A.P \& Hardiningsih (2015) serta Wahyutama (2016), menunjukan bahwa media masa berpengaruh positif terhadap pengungkapan tanggung jawab sosial perusahaan dalam sustainability report.

$\mathrm{H}_{1 \mathrm{e}}$ : Media Masa Berpengaruh Terhadap Pengungkapan Sustainability Report

Maon et al. (2009) menyebutkan bahwa selain pemerintah, masyarakat atau komunitas lokal termasuk kedalam secondary stakeholder. Masyarakat lokal memiliki efek terhadap keputusan manajemen dan juga konsep tanggung jawab sosial yaitu melalui perbedaan norma, harapan sosial, seperti pemantauan dan mekanisme sanksi (Lähdesmäki \& Suutari, 2012). Gunawan (2015) menemukan bahwa masyarakat lokal juga merupakan stakeholder yang paling mempengaruhi praktek pengungkapan sustainability report. Berdasarkan stakeholder theory dan teori legitimasi, masyarakat lokal sebagai bagian dari stakeholder perusahaan memegang peran yang cukup besar karena sebagian besar kegiatan perusahaan. Perusahaan tersebut ikut kedalam kegiatan yang berhubungan dengan masyarakat lokal yang melibatkan tanggung jawab sosial perusahaan karena perusahaan mempunyai tujuan menciptakan pasar yang kompetitif, meningkatkan status ekonomi, dan berkontribusi ke sumber daya manusia dan pengembangan masyarakat (Maimunah et al., 2015).

$\mathrm{H}_{1 \mathrm{f}}$ : Masyarakat Lokal Berpengaruh Terhadap Pengungkapan Sustainability Report.

Sinergi dengan pemasok selaku penyedia barang dan jasa sangat penting untuk mendukung kelancaran proses produksi, sehingga perusahaan akan berusaha untuk menjaga hubungan baik dengan para pemasok (Pramudita \& Dwiyanto, 2017). Tata kelola rantai pasokan perusahaan yang meliputi pengungkapan informasi atas pemasok dapat dilihat dari sustainability report yang publikasi oleh perusahaan. Hasil penelitian Gunawan (2015) menunjukkan bahwa 
pemasok berpengaruh positif terhadap pengungkapan tanggung jawab sosial perusahaan meskipun pemasok memiliki tingkat pengaruh yang paling rendah diantara stakeholder lainnya.

$\mathrm{H}_{1 \mathrm{~g}}$ : Pemasok Berpengaruh Terhadap Pengungkapan Sustainability Report.

Perusahaan-perusahaan yang berpotensi mempunyai dampak lingkungan yang tinggi, cenderung akan mempublikasikan informasi mengenai tanggung jawab sosial secara lebih transparan. Hal tersebut terjadi karena mereka mencoba untuk memperoleh legitimasi. Deegan dan Gordon (1996) menganalisis hubungan antara pengungkapan lingkungan dengan industri tertentu dan juga perubahan pada praktek pelaporan selama periode 1980-1991. Mereka menemukan adanya peningkatan dalam pelaporan tanggung jawab sosial sukarela pada periode tersebut. Kenaikan tingkat transparansi sustainability report mungkin merupakan hasil dari keinginan perusahaan untuk mengurangi persepsi masyarakat akan dampak lingkungan yang lebih besar yang dimiliki industri (Fernandez- Feijoo et al., 2014). Transparansi pengungkapan dari suatau perusahaan dapat menggambarkan statemen tentang perusahaan yang punya potensi pada dampak ke lingkungan. Pernyataan tersebut dibenarkan berdasarkan analisis bahwa kelengkapan laporan tanggung jawab sosial pasti akan diperhatikan pemegang saham apabila perusahaannya berpengaruh pada dampak ke lingkungan agar tetap bercitra baik (Rudyanto \& Siregar, 2018) .

$\mathrm{H}_{1 \mathrm{~h}}$ : Lingkungan Berpengaruh Terhadap Pengungkapan Sustainability Report.

Kelompok kepentingan khusus, kebanyakan LSM diidentifikasikan sebagai stakeholder yang diskresioner. Pengungkapan tentang kelompok ini berisi kolaborasi bersama dengan LSM seperti menyediakan beasiswa untuk kelompok yang kurang beruntung atau dukungan keuangan untuk institusi seperti sekolah atau rumah sakit (Şener et al., 2016). Semakin banyak kelompok kepentingan khusus yang ada dalam perusahaan maka semakin besar juga tekanan yang mereka berikan kepada perusahaan untuk melaporkan aktivitas tanggung jawab sosialnya. Semakin tinggi pengungkapan sustainability report yang diungkapkan oleh perusahaan, maka kelompok kepentingan khusus dalam perusahaan akan merasa puas dan tetap menyediakan dukungan untuk kegiatan operasional perusahaan.

$\mathrm{H}_{1 \mathrm{i}}$ : Kelompok Kepentingan Khusus Berpengaruh Terhadap Pengungkapan Sustainability Report.

Mengacu pada identifikasi stakeholder menurut Freeman (1984), penelitian ini menggunakan pemegang saham, karyawan, konsumen, pemerintah, media masa, masyarakat lokal, pemasok, kelompok pecinta lingkungan, dan kelompok kepentingan khusus sebagai stakeholder. Cornell \& Shapiro (1987) mendefinisikan sekelompok sempit stakeholder, hanya termasuk shareholder, karyawan, dan pelanggan. Sedangkan kelompok stakeholder dalam cakupan kecil menurut Mitchell et al. (1997) adalah mereka yang secara langsung terkait dengan kepentingan ekonomi inti perusahaan. Peneliti lain, Clarkson (1995) mengkasifikasikannya menjadi stakeholder primer dan sekunder; menunjukkan bahwa kelangsungan hidup perusahaan tergantung pada stakeholders utama. Dalam penelitian Şener et al. (2016), berdasarkan hasil analisis kuantitatif tidak ada perbedaan yang signifikan untuk pengungkapan stakeholder yang salience diantara masing-masing industri yang bebeda seperti manufaktur dengan jasa dan 
manufaktur dengan penghasil bahan baku, satu-satunya perbedaan adalah untuk pengungkapan pada pelanggan dan media.

$\mathrm{H}_{2}$ : Salience Stakeholder Tidak Berbeda Antar Sektor Menurut Klasifikasi Sektor di

Bursa Efek Indonesia.

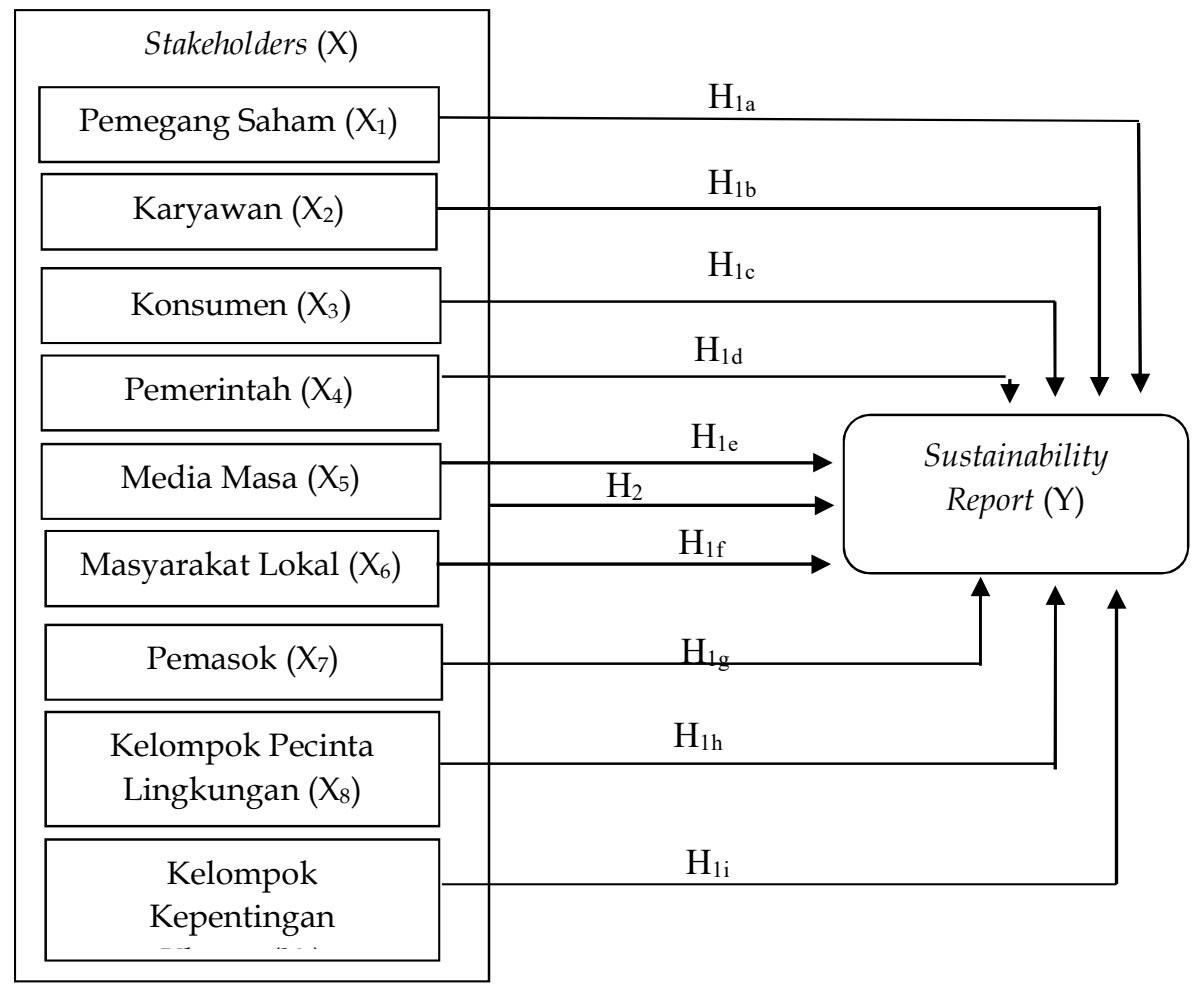

Gambar 1. Model Peneltian

Sumber: Data Penelitian, 2021

\section{METODE PENELITIAN}

Penelitian ini menggunakan metode literasi atau kajian pustaka, yang berarti peneliti menggunakan informasi data yang sudah ada untuk dijadikan bahan analisis (Sugiyono, 2017). Jenis data yang digunakan adalah data kualitatif yang berbentuk kata, kalimat, skema, dan gambar. Dalam penelitian ini data kualitatif yang digunakan berupa sustainability report yang dipublikasikan oleh perusahaan yang terdaftar di Bursa Efek Indonesia dengan periode 2019. Penelitian ini menggunakan pendekatan kuantitatif berbentuk asosiatif karena menguji dua variabel atau lebih (Sugiyono, 2017). Penelitian ini dilakukan untuk mengetahui pengaruh konsistensi atas identifikasi pengaruh stakeholders berdasarkan tingkat pengaruh (salience) stakeholders terhadap pengungkapan sustainability report perusahaan yang dipublikasikan serta pemahaman mengenai kemungkinan adanya perbedaan antara salience stakeholders antar sektor menurut klasifikasi sektor yang terdaftar di Bursa Efek Indonesia. Objek dalam penelitian ini adalah pengungkapan sustainability report perusahaan yang diterbitkan selama tahun 2017 hingga tahun 2019. 
Populasi yang digunakan dalam penelitian ini adalah perusahaan yang terdaftar (listing) di Bursa Efek Indonesia yang meliputi berbagai sektor. Sampel dalam penelitian ini adalah perusahaan yang terdaftar di Bursa Efek Indonesia yang telah mengungkapkan atau mempublikasikan sustainability report. Variabel bebas dalam penelitian ini adalah pemegang saham $\left(X_{1}\right)$, karyawan $\left(X_{2}\right)$, konsumen $\left(X_{3}\right)$, pemerintah $\left(X_{4}\right)$, media masa $\left(X_{5}\right)$, masyarakat lokal $\left(X_{6}\right)$, pemasok $\left(X_{7}\right)$, kelompok pecinta lingkungan $\left(X_{8}\right)$, dan kelompok kepentingan khusus $\left(X_{9}\right)$. Untuk variabel terikat yang digunakan dalam penelitian ini adalah pengungkapan sustainability reporting $(\mathrm{Y})$.

Definisi yang dapat diambil dari statemen sustainability reporting adalah bahwa segala jenis laporan keuangan dengan laporan lain yang terkait seperti nonkeuangan dan aktivitas sosial perusahaan juga termasuk ke dalam laporan sustainability reporting, hal ini terjadi karena pada dasarnya perusahaan dengan lingkungan berkesinambungan (Elkington, 1997). Sesuai dengan pedoman Global Reporting Initiative (GRI), sustainability report dalam penelitian ini diukur dengan Sustainability Report Disclosure Index (SRDI).

Mengacu pada identifikasi stakeholder menurut Freeman (1984) dalam teori stakeholdernya, penelitian ini menggunakan pemegang saham, karyawan, konsumen, pemerintah, media masa, masyarakat lokal, pemasok, kelompok pecinta lingkungan, dan kelompok kepentingan khusus sebagai stakeholder. Adapun stakeholders itu mencakup para pemegang saham, karyawan, konsumen, pemerintah, media masa, rakyat lokal, pemasok, kelompok pecinta lingkungan dan kelompok kepentingan khusus.

Teknik analisis data dalam penelitian ini menggunakan Analisis regresi linier ini digunakan untuk menguji pengaruh parsial variabel independen terhadap variabel dependen dengan melakukan uji asumsi klasik terlebih dahulu yaitu uji normalitas, heterokedastisitas, uji multikolinearitas dan uji autokorelasi. Penelitian ini juga melakukan uji koefisien determinasi (Adjusted $\mathrm{R}^{2}$ ), uji kelayakan model ( $\mathrm{F}$ test), dan uji hipotesis ( $\mathrm{t}$-test). Selain itu penelitian ini juga menggunakan Uji Two Way ANOVA-test. Untuk persamaan umum regresi sebagai berikut.

$\mathrm{SRD}=\alpha+\beta_{1} \mathrm{OWN}+\beta_{2} \mathrm{EMP}+\beta_{3} \mathrm{CON}+\beta_{4} \mathrm{GOV}+\beta_{5} \mathrm{MED}+\beta_{6} \mathrm{LCOM}+\beta_{7} \mathrm{SUP}+$

$\beta_{8} \mathrm{ENV}+\beta_{9} \mathrm{SIG}+\varepsilon$

HASIL DAN PEMBAHASAN

Tabel 1. Hasil Seleksi Pemilihan Sampel

\begin{tabular}{lll}
\hline & Keterangan & Jumlah \\
& Perusahaan \\
\hline Populasi & $\begin{array}{l}\text { Perusahaan Listing di Bursa Efek Indonesia per 2019 } \\
\text { Kriteria }\end{array}$ & 632 \\
& $\begin{array}{l}\text { 1. Perusahaan yang tidak menerbitkan sustainability } \\
\text { report secara konsisten dan terpisah selama periode }\end{array}$ & \\
& (587) \\
& & \\
& 2. Perusahaan yang tidak menggunakan pedoman \\
GRI ataupun tidak mencantumkan Indikator GRI & \\
dalam sustainability report selama periode 2017-2019 & $(2)$ \\
Total perusahaan yang dijadikan sampel & 43 \\
Total data observasi selama tahun 2017 sampai dengan 2019 & 129 \\
\hline
\end{tabular}

Sumber: Data Penelitian, 2021 
Tabel 1, menunjukkan bahwa perusahaan yang terdaftar di Bursa Efek Indonesia per 2020 adalah sebanyak 632 perusahaan. Terdapat 587 perusahaan yang tidak menerbitkan sustainability report secara konsisten dan terpisah selama periode 2017 sampai dengan 2019 dan 2 perusahaan yang tidak menggunakan pedoman GRI ataupun tidak mencantumkan Indikator GRI dalam sustainability report selama periode 2017 sampai dengan 2019. Berdasarkan data tersebut, diperoleh sampel sejumlah 43 perusahaan selama periode penelitian.

\section{Tabel 2. Hasil Statistik Deskriptif setelah outlier}

\begin{tabular}{lccccc}
\hline & $\mathrm{N}$ & Minimum & Maximum & Mean & Std. Deviation \\
\hline Sustainability Report & 106 & 0,05 & 0,51 & 0,2539 & 0,10830 \\
Disclosure Index & 106 & 0,10 & 0,85 & 0,5792 & 0,12452 \\
Pemegang Saham & 106 & 7,11 & 11,44 & 8,7897 & 1,14203 \\
Karyawan & 106 & 0 & 1 & 0,42 & 0,495 \\
Konsumen & 106 & 0 & 1 & 0,42 & 0,495 \\
Pemerintah & 106 & 0 & 1 & 0,83 & 0,377 \\
Media Masa & 106 & 0 & 1 & 0,65 & 0,479 \\
Masyarakat Lokal & 106 & 0 & 1 & 0,43 & 0,498 \\
Pemasok & 106 & 0 & 1 & 0,52 & 0,502 \\
Kelompok Pecinta & 106 & 0 & 1 & 0,67 & 0,473 \\
Lingkungan & & & & & \\
Kelompok Kepentingan & 106 & & & &
\end{tabular}

Sumber: Data Penelitian, 2021

Pengungkapan sustainability report dalam penelitian ini diukur dengan Sustainability Report Disclosure Index (SRDI). Berdasarkan Tabel 2, rata - rata pengungkapan sustainability report menghasilkan nilai 0,253. Mean atau rata-rata nilai 0,253 memiliki arti adanya pendekatan nilai minimum pada rata-rata tersebut. Artinya rata-rata perusahaan punya luas pengungkapan sustainability report yang rendah. Nilai standar deviasi luas pengungkapan sustainability report sejumlah 0,108. Dibandingkan dengan mean ini bernilai lebih rendah. Sehingga rentang data tidak tergolong tinggi dan luas data dari variabel tersebut juga sudah rata.

Dari pengamatan Tabel 2, data pemegang saham menunjukkan rata-rata nilai sejumlah 0,5792, kecenderungan berada dekat dengan nilai maksimum. Dengan demikian tingkat keterlibatan pemegang saham tinggi. Standar deviasi menunjukkan nilai 0,1245 dibawah dari mean yang artinya sebaran datanya sudah rata dan rentangnya tidak terlalu tinggi. Data karyawan menunjukkan mean sejumlah 8,7897, dekat dengan nilai minimum, sehingga rata-rata perusahaan memiliki keterlibatan karyawan rendah. Nilai standar deviasi karyawan sejumlah 1,142 di bawah dari nilai mean sehingga sebaran data sudah merata dan rentang data terggolong rendah. Untuk data konsumen menunjukkan mean-nya adalah 0,42 , dekat dengan nilai minimum sehingga perusahaan memiliki tingkat keterlibatan konsumen yang rendah. Standar Deviasi konsumen berjumlah 0,495 di atas dari mean-nya. Tandanya sebaran dari data konsumen tak rata dan rentangnya tergolong tinggi.

Data pemerintah memiliki nilai mean 0,42, dekat pada nilai minimum sehingga perusahaan memiliki tingkat keterlibatan pemerintah yang rendah. Standar Deviasi pemerintah bernilai 0,495 , di atas nilai mean. Tandanya sebaran 
data pemerintah belum rata dan juga rentang dari datanya tergolong tinggi. Data media menyatakan nilai mean berjumlah 0,83 mendekati nilai maksimum, sehingga perusahaan memiliki tingkat keterlibatan media masa yang rendah. Standar Deviasi media senilai 0,377, lebih rendah dari mean. Disimpulkan bahwa sebaran datanya sudah rata dan rentangnya termasuk rendah.

Berdasarkan Tabel 2, data masyarakat lokal memperlihatkan nilai mean berjumlah 0,65 cenderung mengarah pada nilai maksimumnya sehingga tingkat keterlibatan masyarakat lokal rendah. Standar Deviasinya senilai 0,479 di bawah dari nilai mean-nya, sehingga sebaran datanya sudah merata dengan rentang data tergolong rendah. Data pemasok menerangkan bahwa nilai meannya adalah 0,43 yang dekat dengan nilai maksimumnya, sehingga perusahaan memiliki tingkat keterlibatan pemasok yang rendah. Untuk 0,498 merupakan standar deviasinya dengan nilai itu lebih tinggi daripada meannya. Artinya sebaran data belum rata dan rentang datanya tergolong tinggi.

Berdasarkan Tabel 2, data kelompok pecinta lingkungan memiliki mean yaitu 0,52 yang berada mendekati nilai maksimumnya sehingga perusahaan memiliki tingkat keterlibatan kelompok pecinta lingkungan yang tinggi. Nilai standar deviasi kelompok pecinta lingkungan sebesar 0,502 di bawah dari nilai meannya. Tandanya sebaran datanya sudah rata dan rentang datanya tergolong rendah. Berdasarkan Tabel 2, data kelompok kepentingan khusus memiliki nilai mean sejumlah 0,67 yang cenderung berada dekat dengan nilai maksimumnya sehingga perusahaan memiliki tingkat keterlibatan kelompok kepentingan khusus yang tinggi. Nilai standar deviasi kelompok kepentingan khusus sebesar 0,473 berada di bawah nilai meannya. Dari pernyataan tersebut menyimpulkan bahwa sebaran datanya sudah rata dan rentangnya tergelong rendah.

Tabel 3. Hasil Uji Normalitas setelah outlier

\begin{tabular}{|c|c|}
\hline Kolmogorov-Smirnov Z & Unstandardized Residual \\
\hline $\mathrm{N}$ & 106 \\
\hline Asymp. Sig. (2-tailed) & $0,067 \mathrm{c}$ \\
\hline
\end{tabular}

Sumber: Data Penelitian, 2021

Berdasarkan Tabel 3, dapat dilihat bahwa nilai Asymp. Sig. (2-tailed) sebesar 0,067. Nilai tersebut menunjukkan bahwa nilai Asymp. Sig. (2-tailed) lebih besar dari level of significant 0,05 . Hal ini menunjukkan bahwa data sampel setelah outlier dalam penelitian ini berdistribusi secara normal.

Tabel 4. Hasil Uji Multikolonearitas

\begin{tabular}{lcc}
\hline Variabel & Tolerance & VIF \\
\hline Pemegang Saham & 0,711 & 1,407 \\
Karyawan & 0,773 & 1,294 \\
Konsumen & 0,593 & 1,686 \\
Pemerintah & 0,775 & 1,290 \\
Media Masa & 0,795 & 1,258 \\
Masyarakat Lokal & 0,414 & 2,417 \\
Pemasok & 0,715 & 1,399 \\
Kelompok Pecinta Lingkungan & 0,558 & 1,792 \\
Kelompok Kepentingan Khusus & 0,873 & 1,146 \\
\hline
\end{tabular}

Sumber: Data Penelitian, 2021 
Data diolah menggunakan SPSS dan menjelaskan bahwa tidak adanya saling berkorelasi antara variabel bebas dalam model regresinya. Selain itu nilai VIF dari masing-masing variabel bebasnya kurang dari 10 dan juga tolerance ada pada angka di atas 0,10 (10\%). Dengan demikian dapat ditarik kesimpulan di dalam model regresi antara variabel bebasnya tidak terjadi multikolinearitas.

Tabel 5. Hasil Uji Heterokedastisitas

\begin{tabular}{lllll}
\hline Model & $\mathrm{R}$ & $\mathrm{R}$ Square & Adjusted R Square & Std. Error of the Estimate \\
\hline 1 & $0,291^{\mathrm{a}}$ & 0,085 & $-0,001$ & 0,0112367 \\
\hline
\end{tabular}

Sumber: Data Penelitian, 2021

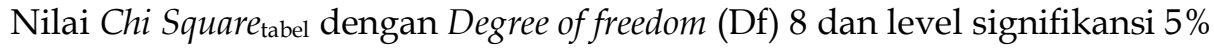

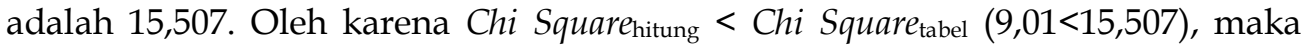
tidak terjadi gejala heteroskedastisitas dalam data penelitian.

Tabel 6. Hasil Uji Autokorelasi menggunakan Run-test

\begin{tabular}{ll}
\hline & Unstandadizeds Residual \\
\hline Test Value $^{a}$ & 0,01100 \\
Casses $<$ Test Vallue & 53 \\
Casses $>=$ Test Vallue & 53 \\
Total Casses & 106 \\
Numbber of Runs & 48 \\
Z, & $-1,171$ \\
Asymp. Sig. (2-tailled) & 0,242 \\
\hline
\end{tabular}

Sumber: Data Penelitian, 2021

Berdasarkan hasil uji autokorelasi menggunakan uji Run-Test pada Tabel 6, nilai Asymp. Sig. (2-tailed) menunjukkan nilai 0,242. Nilai tersebut bernilai lebih besar dari 0,05 sehingga hal tersebut menunjukkan bahwa tidak terdapat gejala atau masalah autokorelasi.

Tabel 7. Hasil Uji Regresi Linier

\begin{tabular}{|c|c|c|c|c|c|c|}
\hline \multirow{2}{*}{\multicolumn{2}{|c|}{ Model }} & \multicolumn{2}{|c|}{$\begin{array}{l}\text { Unstandardizeds } \\
\text { Coefficient }\end{array}$} & \multirow{2}{*}{$\begin{array}{l}\text { Standardizeds } \\
\text { Coefficient } \\
\text { Beta }\end{array}$} & \multirow[t]{2}{*}{$\mathrm{t}$} & \multirow[t]{2}{*}{ Sig. } \\
\hline & & $\mathrm{B}$ & Std. Error & & & \\
\hline \multirow[t]{10}{*}{1} & (Constant) & 0,093 & 0,048 & & 1,936 & 0,056 \\
\hline & Pemegang Saham & 0,278 & 0,081 & 0,320 & 3,445 & 0,001 \\
\hline & Karyawan & $-0,006$ & 0,009 & $-0,067$ & $-0,680$ & 0,498 \\
\hline & Konsumen & $-0,044$ & 0,021 & $-0,201$ & $-2,090$ & 0,039 \\
\hline & Pemerintah & 0,035 & 0,021 & 0,162 & 1,670 & 0,098 \\
\hline & Media Masa & $-0,100$ & 0,026 & $-0,347$ & $-3,778$ & 0,000 \\
\hline & Masyarakat Lokal & 0,037 & 0,022 & 0,164 & 1,695 & 0,093 \\
\hline & Pemasok & 0,031 & 0,021 & 0,143 & 1,478 & 0,142 \\
\hline & $\begin{array}{l}\text { Kelompok Pecinta } \\
\text { Lingkungan }\end{array}$ & 0,044 & 0,021 & 0,203 & 2,111 & 0,037 \\
\hline & $\begin{array}{l}\text { Kelompok } \\
\text { Kepentingan Khusus }\end{array}$ & 0,020 & 0,022 & 0,088 & 0,906 & 0,367 \\
\hline
\end{tabular}

Sumber: Data Penelitian, 2021

Tabel 7, menjelaskan nilai signifikansi pada variabel $\mathrm{X}_{1}$ bernilai $0,001<0,05$ sedangkan $t_{\text {hitung }}$ sejumlah $3,445>t_{\text {tabel }}$ sebesar 1,98498. Hal tersebut mengindikasikan bahwa $\mathrm{H}_{1}$ diterima. Nilai koefisien positif sebesar 0,278 sehingga pemegang saham berpengaruh positif dan signifikan pada pengungkapan sustainability report. Nilai signifikan dari varibael $X_{2}$ sejumlah 0,498 
$>0,05, t_{\text {hitung }}$ nya berjumlah $-0,680<t_{\text {tabel }}$ sebesar 1,98498 , sehingga $\mathrm{H}_{1 \mathrm{~b}}$ ditolak. Nilai koefisien negatif sebesar -0,006 sehingga kepentingan karyawan tidak ada pengaruh signifikan dengan pengungkapan sustainability report. Nilai dari $\mathrm{X}_{3}$ adalah $0,039<0,05$ dan $t_{\text {hitung }}$ nya adalah $-2,090>t_{\text {tabel }}$ sebesar 1,98498 . Hal tersebut mengindikasikan bahwa $\mathrm{H}_{1 c}$ diterima. Nilai koefisien negatif sebesar $-0,044$ sehingga kepentingan konsumen berpengaruh negative dan signifikan pada pengungkapan sustainability report.

Tabel 7, menjelaskan nilai dari $\mathrm{X}_{4}$ sejumlah $0,098>0,05$ dengan $t_{\text {hitung }}$ sejumlah $1,670<t_{\text {tabel }}$ sebesar 1,984 . Hal tersebut mengindikasikan bahwa $\mathrm{H}_{1 \mathrm{~d}}$ ditolak. Nilai koefisien positif sebesar 0,035 sehingga hasil ini mempunyai arti bahwa kepentingan karyawan tidak berpengaruh signifikan terhadap pengungkapan sustainability report. Variabel $\mathrm{X}_{5}$ memiliki nilai signifikan berjumlah $0,000<0,05$ dan $t_{\text {hitung }}$ nya $-3,778>t_{\text {tabel }}$ sebesar 1,984 ini mengindikasikan bahwa $\mathrm{H}_{1 \mathrm{e}}$ diterima. Nilai koefisien negatif sebesar -0,100 sehingga kepentingan media berpengaruh negatif dan signifikan pada pengungkapan sustainability report. Variabel $\mathrm{X}_{6}$ mempunyai nilai signifikan 0,093 $>0,05$ dan $t_{\text {hitung }}$ sejumlah 1,695 $<t_{\text {tabel }}$ sebesar 1,984. Sehingga $\mathrm{H}_{1 \mathrm{f}}$ ditolak. Nilai koefisien positif sebesar 0,037 sehingga kepentingan masyarakat lokal tidak memberikan pengaruh signifikan pada pengungkapan sustainability report.

Tabel 7, menjelaskan bahwa nilai signifikan yang diperoleh $\mathrm{X}_{7}$ sebanyak $0,142>0,05$ dan $t_{\text {hitung }}$ sebanyak $1,478<t_{\text {tabel }}$ sebesar 1,98498, sehingga $\mathrm{H}_{1 \mathrm{~g}}$ ditolak. Nilai koefisien positif sebesar 0,031 oleh karenanya kepentingan pemasok tidak memberikan pengaruh signifikan pada pengungkapan sustainability report. Nilai signifikan X8 sejumlah 0,037<0,05 dan $\mathrm{t}_{\text {hitung }}$ sebanyak 2,111 $>\mathrm{t}_{\text {tabel }}$ sebesar 1,98498, oleh karenanya $\mathrm{H}_{1 \mathrm{~h}}$ diterima. Nilai koefisien positif sebesar 0,044 sehingga kepentingan kelompok pecinta lingkungan berpengaruh positif dan signifikan pada pengungkapan sustainability report. Variabel $X_{9}$ mempunyai nilai signifikan sejumlah 0,367 $>0,05$ dan $t_{\text {hitung }}$ sejumlah $0,906<t_{\text {tabel }}$ sebesar 1,98498, oleh karenanya $\mathrm{H}_{1 \mathrm{i}}$ ditolak. Nilai koefisien positif 0,020 sehingga kelompok kepentingan khusus tidak punya pengaruh signifikan pada pengungkapan sustainability report.

Tabel 8. Hasil Analisis Perbedaan antara Salience Stakeholders Antar Sektor Berdasarkan Klasifikasi Sektor di Bursa Efek Indonesia

\begin{tabular}{lccc}
\hline \multicolumn{1}{c}{ Stakeholder } & Rata-Rata & F & Sig. \\
\hline OWN & 1,740 & 0,383 & 0,683 \\
EMP_Ln & 79,962 & 26,468 & 0,000 \\
CON & 13,860 & 3,153 & 0,079 \\
GOV & 1,347 & 0,298 & 0,586 \\
MED & 16,650 & 3,810 & 0,054 \\
LCOM & 1,561 & 0,346 & 0,558 \\
SUP & 3,283 & 0,730 & 0,395 \\
ENV & 10,465 & 2,363 & 0,127 \\
SIG & 32,904 & 7,809 & 0,006 \\
\hline
\end{tabular}

Sumber: Data Penelitian, 2021

Berdasarkan Tabel 8, hasil analisis Uji ANOVA Two Ways menunjukkan hasil perbedaan antar sektor dalam ketentuan stakeholder, yaitu untuk nilai signifikansi yang lebih dari taraf nyata $(>0,05)$. Hal ini berarti bahwa tidak ada 
perbedaan atas pengaruh variabel bebas terhadap pengungkapan sustainability report antar sektor menurut klasifikasi sektor Bursa Efek Indonesia begitu juga sebaliknya jika nilai signifikansi berada pada nilai kurang dari taraf nyata $(<0,05)$. Hal ini berarti bahwa ada perbedaan pengaruh variabel bebas terhadap pengungkapan sustainability report antar sektor menurut klasifikasi sektor Bursa Efek Indonesia, yang artinya menyimpulkan bahwa $\mathrm{H}_{2}$ diterima

\section{SIMPULAN}

Hasil penelitian ini menunjukkan pemegang saham dan kelompok pecinta lingkungan berpengaruh positif dan signifikan pada luas pengungkapan sustainability report karena memiliki atribut power, legitimasi, dan urgensi sehingga semakin besar tekanan yang diperoleh dari stakeholder tersebut akan semakin meningkatkan kuantitas pengungkapan sustainability report. Sedangkan konsumen serta media masa yang memiliki atribut legitimasi dan power berpengaruh negatif dan signifikan pada luas pengungkapan sustainability report sehingga semakin tinggi tekanan dari kedua stakeholder tersebut akan mengurangi kuantitas pengungkapan sustainability report. Hasil uji ANOVA Two Way menunjukkan tidak ada perbedaan antara variabel pemegang saham, kelompok pecinta lingkungan yang berpengaruh positif dan konsumen, media masa yang berpengaruh negatif dalam pengungkapan sustainability report tiap perusahaan berdasarkan klasifikasi sektor di Bursa Efek Indonesia. Pemenuhan kebutuhan informasi yang tepat sasaran bagi stakeholder akan menjadi nilai tambah bagi perusahaan untuk menciptakan perusahaan yang berkelanjutan.

Penelitian ini hanya menggunakan pemegang saham, karyawan, konsumen, pemerintah, media masa, masyarakat lokal, pemasok, kelompok pecinta lingkungan, dan kelompok kepentingan khusus dalam menentukan luas pengungkapan sustainability report. Peneliti selanjutnya dapat melakukan penelitian serupa dengan mengambil kelompok stakeholder lainnya, periode yang diperpanjang, cara pengukuran variabel yang berbeda, maupun literatur terkait salience stakeholder theory lain agar hasil penelitian yang diperoleh menjadi lebih baik.

\section{REFERENSI}

A.P, W. P., \& Hardiningsih, P. (2015). Pengaruh Agresivitas Pajak Dan media Eksplosure Terhadap Corporate Social Responsibility. Dinamika Akuntansi, Keuangan Dan Perbankan, 4(2), 136-151.

ACCA. (2013). The Business Benefits of Sustainability Reporting in Singapore. In The Association of Chartered Certified Accountants (ACCA) (Issue January). http://www.accaglobal.com/content/dam/acca/global/PDFtechnical/other-PDFs/sustainability-roundtable.pdf

Akrout, M. M., \& Othman, H. Ben. (2013). A Study of the Determinants of Corporate Environmental Disclosure in MENA Emerging Markets. Journal of Reviews on Global Economics, 2, 46-59. https://doi.org/10.6000/19297092.2013.02.5

Alfaiz, D. R., \& Aryati, T. (2019). Pengaruh Tekanan Stakeholder dan Kinerja Keuangan terhadap Kualitas Sistainability Report dengan Komite Audit sebagai Variabel Moderasi. Jurnal Akuntansi Dan Keuangan, 2(2), 112-130. 
Betts, T. K., Wiengarten, F., \& Tadisina, S. K. (2015). Exploring the impact of stakeholder pressure on environmental management strategies at the plant level: What does industry have to do with it? Journal of Cleaner Production, 92, 282-294. https:// doi.org/10.1016/j.jclepro.2015.01.002

Bradford, M., Earp, J. B., \& Williams, P. F. (2017). Understanding sustainability for socially responsible investing and reporting. Journal of Capital Markets Studies, 1(1), 10-35. https://doi.org/10.1108/jcms-10-2017-005

Dewi, K. E. C., \& Sudana, I. P. (2015). Sustainability Reporting Dan Profitabilitas (Studi Pada Pemenang Indonesian Sustainability Reporting Awards). Jurnal Ilmiah Akuntansi Dan Bisnis, 10(1), 1-7.

Dissanayake, D., Tilt, C., \& Xydias-Lobo, M. (2016). Sustainability reporting by publicly listed companies in Sri Lanka. Journal of Cleaner Production, 129, 169182. https:// doi.org/https://doi.org/10.1016/j.jclepro.2016.04.086

Elkington, J. (1997). John Elkington, Cannibals With Forks: The Triple Bottom Line of 21st Century Business. Journal of Business Ethics, 23(2), 229-231. https://doi.org/10.1023/A:1006129603978

Fernandez-Feijoo, B., Romero, S., \& Ruiz, S. (2014a). Effect of Stakeholders' Pressure on Transparency of Sustainability Reports within the GRI Framework. Journal of Business Ethics, 122(1), 53-63. https://doi.org/10.1007/s10551-013-1748-5

Freeman, R. E. E., \& McVea, J. (1984). A Stakeholder Approach to Strategic Management. SSRN Electronic Journal, January. https:// doi.org/10.2139/ssrn.263511

Gunawan, J. (2015). Corporate social disclosures in Indonesia $\square$ : stakeholders ' influence and motivation. Emerald Publishing Limited, 11(3), 535-552. https://doi.org/10.1108/SRJ-04-2014-0048

Hamudiana, A., \& Achmad, T. (2017). Pengaruh Tekanan Stakeholder Terhadap Transparansi Laporan Keberlanjutan Perusahaan-Perusahaan Di Indonesia. Diponegoro Journal of Accounting, 6(4), 1-11.

Huang, C.-L., \& Kung, F.-H. (2010). Drivers of Environmental Disclosure and Stakeholder Expectation: Evidence from Taiwan. Journal of Business Ethics, 96(3), 435-451. https://doi.org/10.1007/s10551-010-0476-3

Lähdesmäki, M., \& Suutari, T. (2012). Keeping at Arm's Length or Searching for Social Proximity? Corporate Social Responsibility as a Reciprocal Process Between Small Businesses and the Local Community. Journal of Business Ethics, 108(4), 481-493. https:// doi.org/10.1007/s10551-011-1104-6

Langrafe, T. de F., Barakat, S. R., Stocker, F., \& Boaventura, J. M. G. (2020). A stakeholder theory approach to creating value in higher education institutions. Emerald Publishing Limited. https:// doi.org/10.1108/BL-03-20200021

Li, D., Lin, H., \& Yang, Y. W. (2016). Does the stakeholders-corporate social responsibility (CSR) relationship exist in emerging countries? Evidence from China. Emerald Publishing Limited, 12(1).

Maimunah, I., Noormi, A. S., \& Roziah, M. R. (2015). Community as stakeholder of the corporate social responsibility programme in Malaysia: outcomes in community development. Social Responsibility Journal, 11(1), 109-130. https:// doi.org/10.1108/SRJ-05-2013-0053. 
Man, C. K. (2015). International Perspectives $\square$ : The impact of Corporate Sustainability Disclosure Decision, Disclosure Quality, Disclosure Quantity, Disclosure Index on Financial Analyst Following, Forecast Accuracy and Forecast Dispersion $\square$ : Evidence from Financial Time. 3.

Maon, F., Lindgreen, A., \& Swaen, V. (2009). Designing and Implementing Corporate Social Responsibility: An Integrative Framework Grounded in Theory and Practice. Journal of Business Ethics, 87(1), 71-89. https:// doi.org/10.1007/s10551-008-9804-2

Mitchell, R. K., Agle, B. R., \& Wood, D. J. (1997). Toward a Theory of Stakeholder Identification and Salience $\square$ : Defining the Principle of Who and What Really Counts. The Academy of Management Review, 22(4), 853-886.

Pramudita, A. P., \& Dwiyanto, B. M. (2017). Faktor-Faktor Yang Mempengaruhi Kinerja Hubungan Pemasok Dan Pembeli Serta Dampaknya Terhadap Keunggulan Bersaing Pada Bisnis Skala Mikro Penyedia Makanan Dan Minuman Di Kawasan Undip Tembalang. Diponegoro Journal of Management, $6(3), 1-14$.

Rudyanto, A., \& Siregar, S. V. (2018). The effect of stakeholder pressure and corporate governance on the sustainability report quality. International Journal of Ethics and Systems, 34(2), 233-249. https://doi.org/10.1108/IJOES-05-20170071

Safitri, D. (2019). Ekolabel Dalam Kajian Pembangunan Berkelanjutan (1st ed.). Pustaka Mandiri.

Sejati, B. P., \& Prastiwi, A. (2015). Pengaruh Pengungkapan Sustainability Report Terhadap Kinerja Dan Nilai Perusahaan. Diponegoro Journal of Accounting, 4(1), 195-206.

Şener, İ., Varoğlu, A., \& Karapolatgil, A. A. (2016). Sustainability Reports Disclosures: Who are the Most Salient Stakeholders? Procedia - Social and Behavioral Sciences, 235, 84-92. https://doi.org/10.1016/j.sbspro.2016.11.028

Simbolon, J., \& Sueb, M. (2016). Pengaruh Pengungkapan Sustainability Report terhadap Kinerja Keuangan Perusahaan (Studi Empiris Pada Perusahaan Yang Terdaftar dalam Bursa Efek Indonesia). Prosiding Simposium Nasional Akuntansi XIX, 1411, 1-30.

Sugiyono. (2017). Metode Penelitian Kuantitatif, Kualitatif, dan RED. CV Alfabeta.

Sun, L., \& Yu, T. R. (2015). The impact of corporate social responsibility on employee performance and cost. Review of Accounting and Finance, 14(3), 262284. https://doi.org/10.1108/RAF-03-2014-0025

Sweeney, L., \& Coughlan, J. (2008). Do different industries report Corporate Social Responsibility differently? An investigation through the lens of stakeholder theory. Journal of Marketing Communications, 14(2), 113-124. https:// doi.org/10.1080/13527260701856657

Wahyutama, N. R. I. (2016). Pengaruh Ukuran Perusahaan, Profitabilitas, Leverage dan Media Exposure Terhadap Corporate Social Responsibility Disclosure. Artikel Ilmiah Mahasiswa 2016 Universitas Jember, 1-8. 